BMJ Nutrition,

Prevention \& Health

\title{
Prevalence and sex-specific patterns of metabolic syndrome in rural Uganda
}

\author{
Limor Ben-Yacov, ${ }^{1}$ Pearl Ainembabazi, ${ }^{1}$ Aliza Hannah Stark, ${ }^{1}$ Samuel Kizito, ${ }^{2}$ \\ Silver Bahendeka ${ }^{3}$
}

To cite: Ben-Yacov L, Ainembabazi P, Stark AH, et al. Prevalence and sexspecific patterns of metabolic syndrome in rural Uganda. $B M J$ Nutrition, Prevention \& Health 2020;3:e000050. doi:10.1136/ bmjnph-2019-000050

${ }^{1}$ School of Nutritional Sciences and the International School of Agricultural Sciences, The Hebrew University of Jerusalem, Rehovot, Israel

${ }^{2}$ Clinical Epidemiology Unit, Makerere University College of Health Sciences, Kampala, Uganda

${ }^{3}$ Medical School, Uganda Martyrs University, Kampala, Uganda

Correspondence to Dr Limor Ben-Yacov, School of Nutritional Sciences, Hebrew University of Jerusalem, Rehovot 76100 , Israel;

limor.ben-yacov@mail.huji.ac.il

Received 28 August 2019 Revised 4 November 2019 Accepted 29 November 2019 Published Online First 2 January 2020

\section{Check for updates}

(C) Author(s) (or their employer(s)) 2020. Re-use permitted under CC BY-NC. No commercial re-use. See rights and permissions. Published by BMJ.

\begin{abstract}
Background and aims In sub-Saharan Africa, infectious diseases are still the leading causes of mortality; however, this may soon be surpassed by noncommunicable illnesses, namely hypertension, diabetes and cardiovascular disease. This study determined the prevalence and patterns of metabolic syndrome and cardio-risk factors in men and women in rural Uganda. Methods A household-based, cross-sectional survey was carried out following the WHO STEP-wise approach to surveillance. It included demographic and lifestyle questionnaires, anthropometric measurements and biochemical analyses. Of the 200 randomly recruited participants, 183 successfully completed two steps of the study and 161 provided blood samples.
\end{abstract}

Results Data were collected from 183 adults, aged 18-69 years; $62 \%$ were female. Based on the National Cholesterol Education Program-Adult Treatment PanelIII criteria, the prevalence of metabolic syndrome was $19.1 \%$ (95\% Cl 14.0 to 22.5). Elevated fasting plasma glucose was observed in $14.2 \%$ (95\% Cl 9.1 to 19.3$)$ of participants, hypertriglyceridaemia in $16.9 \%$ (95\% $\mathrm{Cl} 12.1$ to 23.1); hypertension in $36.1 \%(95 \% \mathrm{Cl} 29.0$ to 43.0$)$ and $52.5 \%(95 \% \mathrm{Cl} 45.2$ to 59.6$)$ had low $\mathrm{HDL}$ (high-density lipoprotein) cholesterol. Abdominal obesity was found in $24.6 \%$ (95\% Cl 18.8 to 31.4 ) of participants. Sex disparities were significant for several risk factors. Females had significantly higher prevalence of abdominal obesity ( $38.6 \%$ vs $1.5 \%$ in males, $p=0.001)$ and twice the rates of low HDL ( $65.8 \%$ vs $30.4 \%, p=0.001)$. Men tended to have higher but not significant rates of hypertension $(42.0 \%$ vs $32.5 \%)$ and smoked significantly more than women $(49.3 \%$ vs $21.1 \%, p<0.001)$. Alcohol consumption was also higher in men $(55.1 \%$ vs $18.4 \%, p<0.001)$ and quantities consumed were approximately three times greater than in females $(p<0.001)$.

Conclusion Metabolic syndrome exists at worrying rates in the rural Ugandan population. Sex disparities are evident in risk factor prevalence, reflecting physiological variables and deeply entrenched cultural and lifestyle norms.

\section{INTRODUCTION}

Metabolic syndrome (MetS) is a group of risk factors that increases the likelihood of developing cardiovascular disease (CVD). In the USA, the National Cholesterol Education Program (NCEP III) defines metabolic syndrome as the presence of at least three of the following risk factors: abdominal obesity,
What this paper adds

- A high prevalence of metabolic syndrome was documented in a rural Ugandan adult population.

- Distinct sex-specific patterns of metabolic syndrome were identified.

- Sex specific disparities in metabolic syndrome components and other cardiovascular risk factors were consistent with findings from other Sub-Saharan countries.

elevated plasma fasting glucose, increased blood pressure, elevated plasma triglycerides (TG) and low levels of plasma high-density lipoprotein cholesterol (HDL-C). ${ }^{1}$ Additional cardiovascular risk factors have been documented including: low levels of physical activity, high body mass index (BMI), smoking and alcohol consumption. ${ }^{12}$ CVDs are the leading cause of death globally. ${ }^{3}$ Furthermore, the Global Status Report on Non-Communicable Diseases documented that three quarters of all CVD deaths and the majority of premature deaths $(82 \%)$ occur in low-income and middle-income countries like Uganda. ${ }^{34}$

In the 1950 s, coronary heart disease was virtually non-existent in Uganda. ${ }^{4}$ However, mortality rates from non-communicable diseases (NCDs) are rising and have reached an estimated $27 \%,{ }^{4}$ with heart disease currently listed by the Global Burden of Disease Study among the top 10 causes of death in Uganda. ${ }^{5}$ Infectious diseases such as malaria and HIV/ AIDS remain the leading causes of death, but intensive efforts are being made to improve disease outcomes. These changes in disease prevalence, with the rise of NCDs, reflect an epidemiologic transition.

Indeed, findings from the National NonCommunicable Diseases Risk Factor Survey, that was carried out in Uganda in 2014, documented $26.4 \%$ and $36.9 \%$ rates of hypertension and prehypertension, respectively. ${ }^{6}$ Even 
more disquieting was that only $7.7 \%$ of participants were aware of their blood pressure status. ${ }^{7}$

Other risk factors, such as low HDL-C, have also been documented in rural areas of Uganda with rates of prevalence as high as $71.3 \%$ in the adult population. ${ }^{8}$ Additionally, in recent population-based surveys, $2.0 \%-$ $8.6 \%$ prevalence rates of impaired fasting glucose and $1.4 \%-7.4 \%$ prevalence of diabetes mellitus have been reported. $^{910}$

Although the individual risk factors for CVD have been well documented in Uganda, similar data on the prevalence of MetS are not available. Yet, MetS is considered to be more predictive of NCDs and a valuable measure for identifying both new onset diabetes and CVD. ${ }^{11}$ Several underlying factors are considered responsible for the development of MetS and insulin resistance is central to metabolic physiological disruption. Insulin resistance is linked to elevated free fatty acid levels. In addition, it is responsible for abnormal adipokine profiles such as adiponectin, which effects glucose metabolism and leptin activity. ${ }^{12}$

To the best of our knowledge, no study has been designed with the objective of determining the prevalence of metabolic syndrome among a random sample of adults in rural Uganda.

\section{METHODS}

\section{Study population and design}

A cross-sectional study was carried out in two representative districts (Ntungamo and Sheema) in rural south western Uganda. Sampling techniques that were used in selecting study participants included the probability proportional to size technique ${ }^{13}$ for random sampling and the KISH Grid method. ${ }^{14}$ A household was defined as a group of people living and eating together. ${ }^{9}$ A single resident member was selected from each household without replacement. ${ }^{14}$ Inclusion criteria were males or non-pregnant females, aged 18-69 years, of African Ugandan descent, who had lived in the villages for the past 6 months. Exclusion criteria included history of or current mental illness or inability to provide informed consent.

\section{Demographics, anthropometric and laboratory measurements}

Data collection followed an abridged version of the WHO STEP-wise approach to surveillance (STEPS) method. ${ }^{15}$

Step 1 involved administering a questionnaire to collect information on social demographics, including marital status, level of education, occupation and housing conditions. Lifestyle assessment was determined based on previously validated questions regarding tobacco use ${ }^{6}$ alcohol use $^{616}$ and physical activity. ${ }^{17}$

Step 2 of the WHO STEPS was carried out by taking physical measurements such as weight, height, waist and hip circumference ${ }^{18}$ and blood pressure..$^{15}$ All readings were measured in triplicate and the average of the three taken as the final value, except for blood pressure, where the first reading was discarded. Waist circumference was measured to the nearest $0.1 \mathrm{~cm}$ using a non-stretchable standard tape measure. The waist was identified as the point mid-way between the lowest rib and the top of the iliac crest on exhalation. ${ }^{18}$

Step 3 was the collection of fasting blood samples from participants. Plasma glucose levels were measured with Haemocue analyzers using finger prick drawn blood. In addition, $5 \mathrm{~mL}$ of venous blood was drawn from each participant into a vacutainer bottle. Samples were centrifuged and the serum was transported on ice packs to St. Francis Hospital Laboratory, in Kampala. Samples were stored at $-70^{\circ} \mathrm{C}$. The serum sample was analysed for HDL-C and TG.

Physical activity levels were determined by estimating minutes per week achieved from moderate-intensity and vigorous-intensity activities for work, transportation and leisure, based on WHO criteria. $^{17}$

\section{Definitions}

Participants with a reading $\geq 100 \mathrm{mg} / \mathrm{dL}$ were considered to have elevated fasting plasma glucose, a reading $\geq 100 \mathrm{mg} / \mathrm{dL}$ to $<126 \mathrm{mg} / \mathrm{dL}$ was classified as prediabetes and $\geq 126 \mathrm{mg} / \mathrm{dL}$ was classified as diabetes. ${ }^{1}$ Elevated TG were defined as $\geq 150 \mathrm{mg} / \mathrm{dL}$, low HDL-C as $<40 \mathrm{mg} / \mathrm{dL}$ in men or $<50 \mathrm{mg} / \mathrm{dL}$ in women. ${ }^{1}$ Individuals that reached at least 600 metabolic equivalent of task were classified as physically active. $^{17}$

Metabolic syndrome was defined according to the ATP/NCEP III definition, ${ }^{1}$ as presence of any three of the following: waist circumference $\geq 102 \mathrm{~cm}$ in men or $\geq 88 \mathrm{~cm}$ in women; blood pressure $\geq 130 \geq 85 \mathrm{~mm} \mathrm{Hg}$; fasting blood glucose $\geq 100 \mathrm{mg} / \mathrm{dL} ; \mathrm{TG} \geq 150 \mathrm{mg} / \mathrm{dL}$ and low HDL-C $<40 \mathrm{mg} / \mathrm{dL}$ in men or $<50 \mathrm{mg} / \mathrm{dL}$ in women.

\section{Statistical analyses}

Continuous variables were summarised using mean $\pm \mathrm{SD}$, and the categorical variables were summarised using frequencies and proportions, with the corresponding 95\% CIs. Logistic regression models were used to determine factors associated with metabolic syndrome. Multivariate logistic regression was performed to determine how the independent variables were jointly associated with the outcome. Variables with a $\mathrm{p} \leq 0.2$ at bivariate analysis were considered for the multivariate model. The variables were entered into a stepwise logistic model. Interaction between the variables which remained in the model was assessed using the Chunk test. This was then followed by assessing for confounding using a difference of $\geq 10 \%$ between the crude and adjusted measure of effect (OR) for the variables that would have gone out at each step. Significance was set at $p<0.05$. The goodness of fit of the final models was assessed using the Hosmer and Lemeshow Statistic, using the estat gof command in Stata V.14.1 (Stata, College Station, Texas, 2015). 
Table 1 Demographics of the study population

\begin{tabular}{|c|c|c|c|c|}
\hline \multirow[b]{2}{*}{ Variable } & \multirow{2}{*}{$\begin{array}{l}\text { Overall proportion }(n) \\
n=183\end{array}$} & \multirow{2}{*}{$\begin{array}{l}\text { Male proportion (n) } \\
\mathrm{n}=69\end{array}$} & \multirow{2}{*}{$\begin{array}{l}\text { Female proportion }(\mathrm{n}) \\
\mathrm{n}=114\end{array}$} & \multirow[b]{2}{*}{$P$ value } \\
\hline & & & & \\
\hline Age (vears) Mean \pm SD & $44.2 \pm 13.1$ & $44.5 \pm 14.7$ & $44.1 \pm 12.2$ & 0.576 \\
\hline Married & $73.2 \%(134)$ & $88.4 \%(61)$ & $64.0 \%(73)$ & $<0.001$ \\
\hline Single & $8.7 \%(16)$ & $10.1 \%(7)$ & $7.9 \%(9)$ & \\
\hline \multicolumn{5}{|l|}{ Highest level of education attained } \\
\hline No formal education & $23.5 \%(43)$ & $15.9 \%(11)$ & $28.1 \%(32)$ & 0.001 \\
\hline Primary & $48.1 \%(88)$ & $40.6 \%(28)$ & $52.6 \%(60)$ & \\
\hline Secondary & $20.8 \%(38)$ & $27.5 \%(19)$ & $16.7 \%(19)$ & \\
\hline Iron sheets, concrete walls, no solar & $38.8 \%(71)$ & $36.2 \%(25)$ & $40.4 \%(46)$ & \\
\hline Iron sheets, mud and wattle walls, no solar & $11.5 \%(21)$ & $11.6 \%(8)$ & $11.4 \%(13)$ & \\
\hline Mud and wattle, grass thatched, no solar & $5.5 \%(10)$ & $7.3 \%(5)$ & $4.4 \%(5)$ & \\
\hline
\end{tabular}

Bold values represent significant differences $(p<0.05)$

\section{Ethical approval}

The study was approved by the St. Francis Hospital Review and Ethics Committee (Document No. UG-REC-020) and the Uganda National Council of Science and Technology (Document No. HS2218). Information leaflets which were translated into the local language (Runyankole) were provided and individuals were asked for written informed consent before they participated in the study. In cases where the consent could not be expressed in writing, oral consent was obtained.

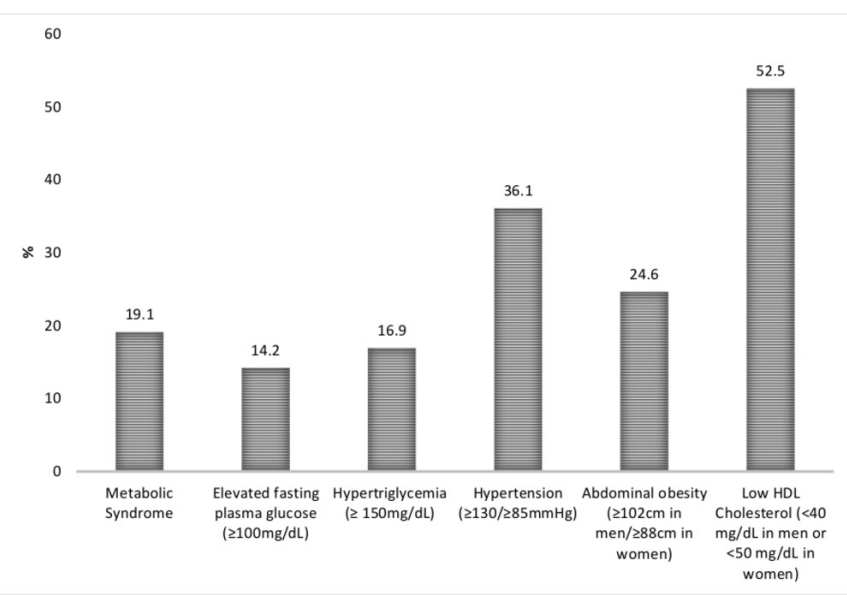

Figure 1 Prevalence of metabolic syndrome and its components in rural residents in Uganda $(n=161)$. HDL, highdensity lipoprotein.

\section{RESULTS}

Out of the 200 recruited participants, 183 successfully completed two steps of the study and 161 completed all three steps. Seventeen individuals declined to participate, and 22 did not complete the blood draw. Demographic characteristics are summarised in table 1.

The mean age of participants was 44 years, ranging from 18 to 69 years with no significant difference between sexes. More than half of the participants were female $(62 \%)$, married $(73 \%)$ and had completed at least primary education (75\%). Almost half (44\%) of the study population reported to have access to solar power, which reflects a socioeconomic status above the poverty line. ${ }^{19}$

Prevalence of metabolic syndrome and its components for participants $(\mathrm{n}=161)$ are shown in figure 1. Overall, $19.1 \%$ (95\% CI 14.0 to 22.5 ) of the study population met the criteria for metabolic syndrome. Notable results include $52.5 \%$ (95\% CI 45.2 to 59.6) of participants with low levels of HDL-C and $36.1 \%$ (95\% CI 29.0 to 43.0) of participants with hypertension. Significant differences in the prevalence of specific risk factors between sexes were also observed as presented in figure 2. Twice as many women than men were documented with low HDL $(p=0.001)$. In addition, almost all the cases of abdominal obesity were measured in women $(p=0.001)$. Men tended to have higher rates of hypertension and elevated TG, but results did not reach statistical significance.

Evaluation of modifiable CVD risk factors using a multivariate analysis, adjusted for: age, sex, smoking status, physical activity, housing status, self-reported family history of diabetes or hypertension, indicated that overweight participants $\left(29.9 \geq \mathrm{BMI} \geq 25.0 \mathrm{~kg} / \mathrm{m}^{2}\right)$ had 11.2 


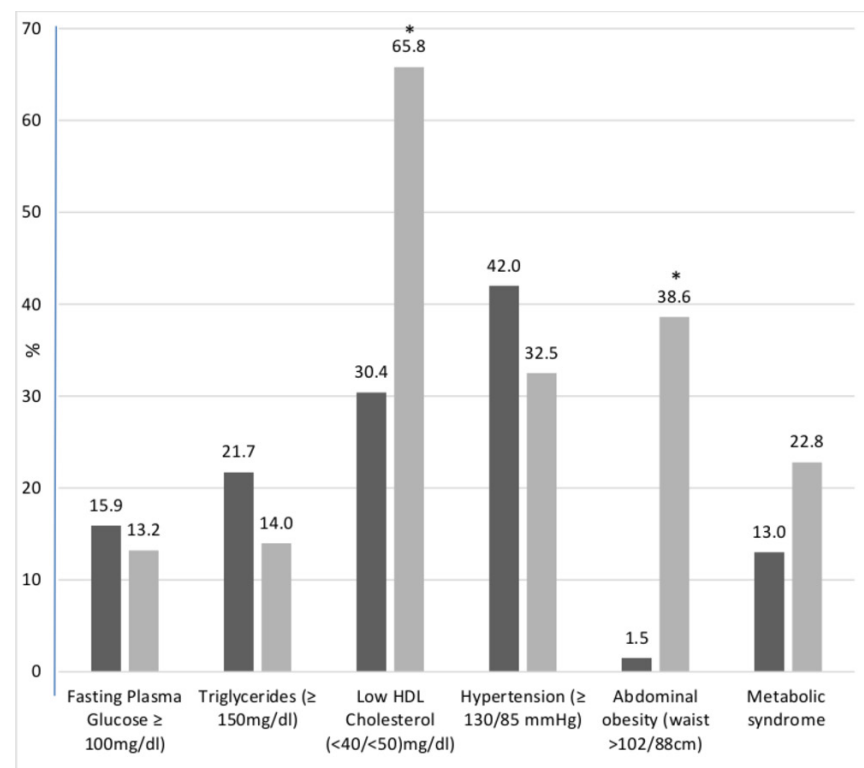

- Men $=$ Women

Figure 2 Prevalence of the components of metabolic syndrome in rural Ugandans $(n=161)$ by sex. HDL, highdensity lipoprotein.

times greater odds of being diagnosed with metabolic syndrome (95\% CI 2.8 to $44.9, \mathrm{p}=0.001$ ) compared with participants in the normal BMI range $\left(18.5-24.9 \mathrm{~kg} / \mathrm{m}^{2}\right)$. Likewise, obese participants (BMI $\geq 30 \mathrm{~kg} / \mathrm{m}^{2}$ ) had 20.3fold increased odds for metabolic syndrome (95\% CI 3.4 to $122.5, \mathrm{p}=0.001$ ).

The prevalence of additional risk factors of metabolic disease such as BMI, smoking, alcohol consumption and physical activity status are not part of the NCEP-ATP III criteria. This data are presented in table 2.

Half of the participants had a normal BMI, while around $40 \%$ had elevated weight. Significantly more women were classified as overweight than men $(27.2 \%$ vs $15.9 \%, \mathrm{p}=0.001$ ) and all documented cases of obesity were found only in women $(26.3 \%, \mathrm{p}=0.001)$.

The majority of the participants $(83.1 \%)$ met WHO recommendations for physical activity. Almost a third of the population were current or ever smokers. However, $79.2 \%$ of females reported that they had never smoked. Men smoked more than twice as much as women $(49.3 \%$ vs $21.1 \%, \mathrm{p}<0.001)$ and the majority of both male smokers $(94.1 \%)$ and female smokers $(79.2 \%)$ smoked on a daily basis. Differences in the mode of tobacco use were found with nearly all men smoking cigarettes or pipes while more women chewed tobacco $(\mathrm{p}=0.004$, table 2$)$. A third of the overall population also reported that they were current drinkers. Most of drinkers were men $(55.1 \%$ vs $18.4 \%$ in women, $\mathrm{p}<0.001$ ), and, when drinking, men consumed three times more alcohol compared with women $(\mathrm{p}<0.001)$.

\section{DISCUSSION}

This study is the first population-based study, in a representative sample of adults, to document that metabolic syndrome (MetS) exists at a disturbing rate of $19 \%$ in rural Uganda. Previous assessments documented 4\%-14\%; however, study populations included children as young as $13^{20}$ or patients with AIDS. ${ }^{21}$

The major risk factors identified in this study were: reduced levels of HDL-C, hypertension and high waist circumference, a variable not reported in the National 2014 Survey. ${ }^{6}$ An intriguing picture was revealed when comparing the prevalence of cardio-risk factors between men and women (figure 2). Although the difference in the overall prevalence of MetS by sex did not reach significance, distinctive, sex-specific patterns of the three most common risk factors were noteworthy. Females accounted for almost all the cases of abdominal obesity (39\% vs $2 \%$ in males) and twice as many women than men were identified with low HDL levels (66\% vs $30 \%$ ). In addition, there was a distinct trend towards higher rates of hypertension in males $(42 \%)$ compared with their female counterparts $(33 \%)$.

Similar to the findings of this study, Asiki $e t$ al reported low HDL-C levels in Ugandan women with rates of $79 \%$ in women vs $61 \%$ in men. Another variable exhibiting substantial sex differences in the current study was abdominal obesity. This result confirmed the work of Murphy and colleagues who reported abdominal obesity rates of $2 \%$ in rural Ugandan men vs $30 \%$ in women. ${ }^{20}$ Last, the current results of $29 \%$ more hypertension in males compared with females, though not significant, are supported by findings of in the Ugandan National Survey, where $14 \%$ greater risk of hypertension was documented in males. ${ }^{6}$ Prevalence of MetS in adults has also been reported in other sub-Saharan African (SSA) countries, including Ghana $(12 \%),{ }^{22}$ Cameroon $(11 \%)^{23}$ Kenya $(35 \%)^{24}$ and Tanzania $(38 \%) .{ }^{25}$ Surprisingly, some of these rates are comparable to the USA with approximately $34 \%$ of the population suffering from MetS. ${ }^{26} 27$ This may reflect adaptation of unhealthy Western lifestyle practices in African countries. Although these data have been reported for both urban and rural settings, there is no agreement regarding the impact of place of residence on MetS prevalence. Heterogeneity in results may be explained by variable socioeconomic status and rapid changes in environmental factors. ${ }^{28}$

In order to verify the possibility of a sex-specific pattern for metabolic disorders, comparisons to other studies in SSA countries were made. Higher prevalence of low levels of HDL in women in comparison to men has repeatedly been documented. In Nigeria, rates of $83 \%$ were determined in women compared with $52 \%$ in men, ${ }^{29}$ while Kenya reported $72 \%$ in women vs $45 \%$ of men. ${ }^{24}$ Tanzania documented low levels of HDL-C in $48 \%$ of females and $22 \%$ of males. ${ }^{25}$ In contrast, and not in line with our study results, the National Survey in Uganda ${ }^{6}$ reported overall equal rates of $61 \%$ low HDL-C in both male and female Ugandan subjects living in rural areas. 
Table 2 Life style characteristics of the study population by sex

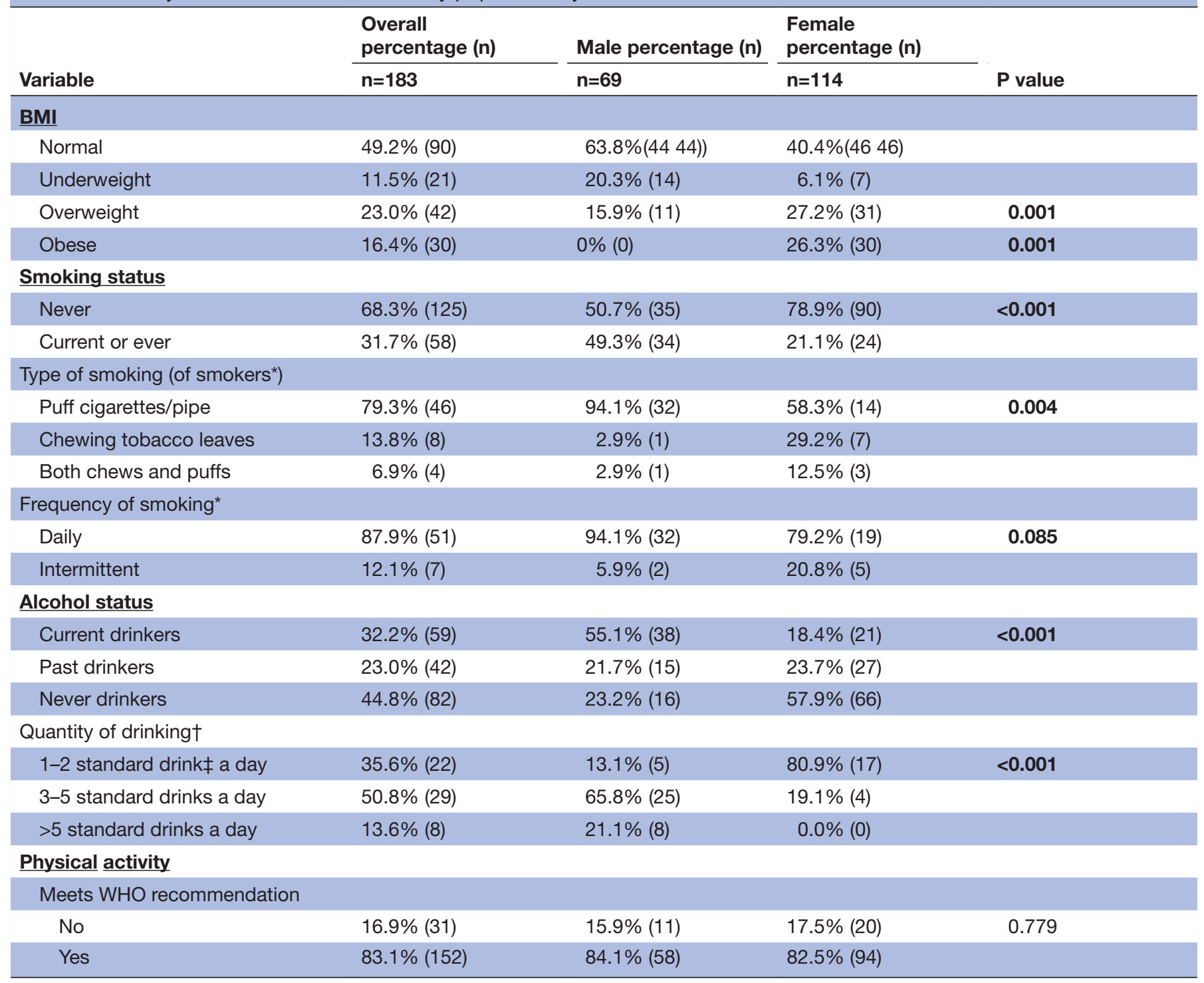

Bold values represent significant differences $(p<0.05)$

${ }^{*}$ Of current or ever smokers.

†Of current drinkers.

†Standard drink of alcohol: any alcohol drink that contains $10 \mathrm{~g}$ pure alcohol (WHO 2000). Equivalents of 1 standard alcoholic drink include; $285 \mathrm{~mL}$ (one bottle) of beer, $100 \mathrm{~mL}$ glass of wine (factory distilled or locally brewed) and $30 \mathrm{~mL}$ glass of a spirit or gin (factory distilled or locally brewed). ${ }^{16}$

Abdominal obesity has also been documented to be sex-specific in several studies in SSA countries, with substantially higher rates in women. It is considered to be the high-risk body fat pattern, as this adipose tissue is particularly active hormonally, secreting a wide variety of adipokines. It is associated with greater insulin resistance and dyslipidaemia. ${ }^{30}$ In Benin $54 \%$ of women were identified with abdominal obesity vs $11 \%$ in men. ${ }^{31}$ Two studies in urban Tanzania showed a five times higher prevalence rates among women ( $58 \%$ vs $11 \%$ and $35 \%$ vs $7 \%)^{25} 32$ Moreover, following logistic regression analyses of the Tanzanian data, women had 14.2-fold increased odds for abdominal adiposity than men $(95 \%$ CI 5.8 to 34.6$){ }^{25}$ Abdominal obesity, in all these studies, was defined using the WHO criteria of waist circumference $\geq 102 \mathrm{~cm}$ in men and $\geq 88 \mathrm{~cm}$ in women. ${ }^{18}$

Since the best cut-off point has been widely debated, in particular for individuals living in SSA, some studies have used a more stringent standard of $\geq 94 \mathrm{~cm}$ in men and $\geq 80 \mathrm{~cm}$ in women. ${ }^{33}$ This was the case in a Kenyan study that reported prevalence of abdominal obesity in $70 \%$ of urban women vs 30\% in urban men. ${ }^{24}$ In Cameroon, $33 \%$ of females and only $4 \%$ of males suffered from abdominal obesity. The participants in Cameroon were relatively young, 20-25 years old, with an overall rate of MetS of $11 \%{ }^{23}$

Sex differences in the prevalence of hypertension, though not significant in this study, were still $29 \%$ higher 
in men than women. This trend was supported by a significant $14 \%$ higher rate of hypertension in men, found in 3906 Ugandans participating in the National Survey. ${ }^{6}$ In an additional study, this CVD risk factor was significantly lower among women than men (OR 0.67) as determined in 2011 participants from northwestern Tanzania and southern Uganda. ${ }^{34}$ Additional studies from Tanzania ${ }^{24}$ and Kenya ${ }^{23}$ report the same pattern, indicating that hypertension is more prevalent in men in SSA.

Possible mechanisms responsible for the sex-specific risk factors of CVD include inactivity, tobacco use, alcohol intake and obesity. ${ }^{35}$ These are all common behavioural risk factors for NCDs which we found to be prevalent at significantly different levels in African men and women. However, in this study, physical activity levels were similar for both sexes (table 2). It should be noted that there is disagreement regarding the WHO methodology for measurement of physical activity, which has been shown to have low validity in Africa. ${ }^{36}$

Data reported here indicate that men smoked significantly more than women and drank alcohol significantly more than women. These results are in line with the Ugandan 2014 National Survey. Adjusting for age, sex, region of residence and ethnicity, males were found to consume twice as much alcohol as women $(\mathrm{OR}=2.34$, 95\% CI 1.88 to 2.91$).{ }^{16}$ Similar results on higher rates of smoking and alcohol consumption in men have been published for urban Tanzania, ${ }^{2532}$ Benin $^{31}$ and other SSA countries. ${ }^{37}$ Lifestyle behaviours, such as higher rates of smoking in men, have known hypertensive effects, including stimulating the sympathetic nervous system, which leads to arterial stiffness. ${ }^{38}$

Overweight and obesity, along with higher rates of abdominal obesity, were the major factors contributing to high rates of MetS identified in females. Although dietary consumption was assessed in this study, due to the challenges of collecting data in populations with limited literacy, it was not possible to accurately determine total energy and nutrient intake. However, a dietary diversity score was calculated and was similar in both sexes (data not shown). Female gender has previously been documented as a predictor of overweight and obesity in periurban and rural Uganda ${ }^{39}$ along with other SSA countries. For example, in Tanzania, women had 4.3 greater odds of obesity than men. ${ }^{25} 32$ This is most likely linked to a multitude of African social and cultural factors. ${ }^{38}$ When a young Ugandan woman is being prepared for marriage, her diet and activity are planned in ways guaranteed to increase her weight. ${ }^{25} 39$ The bride-to-be is not allowed to carry out heavy physical activity and is encouraged to eat large quantities of food. Interestingly, higher rates of abdominal obesity in women have also been documented in the USA, despite social and cultural pressures promoting a slim body image. This sex gap in abdominal obesity has intensified in the last decades, reaching $70 \%$ in American woman vs $41 \%$ in men in $2014 .{ }^{27}$

Hyperglycaemia is also part of the MetS. Although significant sex differences were not observed in this study, the prevalence of diabetes has been reported to be higher in women compared with men across all age groups in SSA. ${ }^{28}$ This contradicts the hypothesis that higher levels of oestrogen in women are thought to protect pancreatic beta cells. ${ }^{40}$ In this study, other factors, such as significantly more smoking in men, may have contributed to similar data documented for both men and women.

This study has many strengths. Participants were randomly recruited and sample size had sufficient power to reach significant results. The use of biochemical data and anthropometric measurements allowed for objective documentation without relying on self-reported data. Study limitations included challenges associated with carrying out research in rural African settings, characterised by populations with low levels of education. This was reflected in distrust and superstition, which possibly led to individuals' unwillingness to participate in a study that involved drawing blood. It is likely that some participants believed that researchers were investigating topics related to HIV, ${ }^{41}{ }^{42}$ which may have reduced compliance. Therefore, the study staff did not ask about HIV status or use of antiretroviral drugs.

In conclusion, metabolic syndrome exists at worrying rates in the rural Ugandan population. Distinct sexspecific patterns of risk factors for MetS and CVD were documented and are likely due to complex interactions of lifestyle behaviours, physiological variables and cultural influences. Despite the rapid increase in prevalence of NCDs in SSA, awareness of the problem is still low. Thus, multidisciplinary interventions to reduce risk factors should be a top priority at all healthcare levels taking into consideration disparities between men and women.

Acknowledgements The authors would like to thank the men and women in Uganda who consented to participate in this study. In addition, the study would not have been possible without the financial support of the Pears Foundation (UK) and The Hebrew University of Jerusalem, International School of Agricultural Sciences who provided a scholarship for Ms Ainembabazi in her MSc studies. DAS Handling Ltd, Uganda, also provided partial financial support for this study.

Contributors LB-Y was involved in all stages of the research. She was responsible for the overall planning and design of the study, data interpretation and drafting the initial manuscript. PA was an MSc student on this project and participated in study design, was responsible for data and sample collection and processing and final review of the manuscript. AHS served as a consultant throughout the research and was involved in manuscript writing. SK performed statistical analysis and final review of the manuscript. SB was involved in the study design, was responsible for laboratory analyses and supervising the field work from start to finish. He also critically reviewed the final version of the manuscript.

Funding This study was funded by Pears Foundation (UK), DAS Handling Ltd (Uganda).

Competing interests None declared.

Patient consent for publication Not required.

Provenance and peer review Not commissioned; externally peer reviewed.

Data availability statement Data are available on reasonable request.

Open access This is an open access article distributed in accordance with the Creative Commons Attribution Non Commercial (CC BY-NC 4.0) license, which permits others to distribute, remix, adapt, build upon this work noncommercially, and license their derivative works on different terms, provided the original work is properly cited, appropriate credit is given, any changes made indicated, and the use is non-commercial. See: http://creativecommons.org/ licenses/by-nc/4.0/. 


\section{REFERENCES}

1 National Cholesterol Education Program. Third report of the National cholesterol education program (NCEP) expert panel on detection, evaluation, and treatment of high blood cholesterol in adults (adult treatment panel III) final report. Circulation 2002;106:3143-421.

2 American Heart Association. Metabolic syndrome, 2016. Available: https://www.heart.org/en/health-topics/metabolic-syndrome/aboutmetabolic-syndrome [Accessed 4 Jul 2019].

3 World Health Organization (WHO). Global status report on noncommunicable diseases, 2014. Available: http://www.who.int/nmh/ publications/ncd-status-report-2014/en/.pdf [Accessed 4 Jul 2019].

4 World Health Organization (WHO). Non-Communicable diseases (Ncd) Uganda profile. Available: http://www.who.int/nmh/countries/ uga_en.pdf?ua=1.pdf [Accessed 4 Jul 2019].

5 Institute for Health Metrics and Evaluation. Global burden of diseases profile: Uganda, 2017. Available: http://www.healthdata.org/uganda. pdf [Accessed 4 Jul 2019].

6 Ministry of Health. Non-Communicable disease risk factor survey, Uganda report, 2014. Available: https://www.health.go.ug/content/ non-\%C2\%ADcommunicable-disease-risk-factor-baseline-survey. pdf [Accessed 4 Jul 2019 4].

7 Guwatudde D, Mutungi G, Wesonga R, et al. The epidemiology of hypertension in Uganda: findings from the National noncommunicable diseases risk factor survey. PLoS One 2015;10:e0138991.

8 Asiki G, Murphy GAV, Baisley K, et al. Prevalence of dyslipidaemia and associated risk factors in a rural population in south-western Uganda: a community based survey. PLoS One 2015;10:e0126166.

9 Bahendeka S, Wesonga R, Mutungi G, et al. Prevalence and correlates of diabetes mellitus in Uganda: a population-based national survey. Trop Med Int Health 2016;21:405-16.

10 Mayega RW, Guwatudde D, Makumbi F, et al. Diabetes and prediabetes among persons aged 35 to 60 years in eastern Uganda: prevalence and associated factors. PLoS One 2013;8:e72554.

11 Grundy SM. Pre-Diabetes, metabolic syndrome, and cardiovascular risk. J Am Coll Cardiol 2012;59:635-43.

12 Lam DW, LeRoith D. Metabolic Syndrome. In: Feingold KR, Anawalt B, Boyce A, eds. Endotext. South Dartmouth (MA): MDText.com, Inc, 2000.

13 Turner AG. Sampling strategies. Handbook on designing of household sample surveys. Geneva: United Nations Statistics Division, 2003

14 Kish L. Survey sampling. New York: John Wiley and Sons, 1965.

15 World Health Organization. Who steps surveillance manual: the who stepwise approach to chronic disease risk factor surveillance, 2005. Available: https://apps.who.int/iris/handle/10665/43376.pdf [Accessed 4 Jul 2019].

16 Kabwama SN, Ndyanabangi S, Mutungi G, et al. Alcohol use among adults in Uganda: findings from the countrywide non-communicable diseases risk factor cross-sectional survey. Glob Health Action 2016;9:31302.

17 World Health Organization. Global physical activity questionnaire (GPAQ). analysis guide, 2012. Available: https://www.who.int/ncds/ surveillance/steps/GPAQ_EN.pdf [Accessed 4 Jul 2019].

18 World Health Organization. Waist circumference and waist-hip ratio: report of a who expert consultation, 2008. Available: https://www.who.int/nutrition/publications/obesity/WHO_report waistcircumference_and_waisthip_ratio/en. pdf [Accessed cited 2019 July 4].

19 Lay J, Ondraczek J, Stoever J. Renewables in the energy transition: evidence on solar home systems and lighting fuel choice in Kenya. Energy Economics 2013;40:350-9.

20 Murphy GAV, Asiki G, Young EH, et al. Cardiometabolic risk in a rural Ugandan population. Diabetes Care 2013;36:e143.

21 Muyanja D, Muzoora C, Muyingo A, et al. High prevalence of metabolic syndrome and cardiovascular disease risk among people with HIV on stable art in southwestern Uganda. AIDS Patient Care STDS 2016;30:4-10.

22 Ofori-Asenso R, Agyeman AA, Laar A. Metabolic syndrome in apparently "healthy" Ghanaian adults: a systematic review and metaanalysis. Int J Chronic Dis 2017;2017:1-9.

23 Dabou S, Telefo PB, Fonkeng Sama L. Evaluation of dietary habits and lifestyle on the prevalence of metabolic syndrome and obesity in undergraduate university students in Cameroon: a cross sectional study. J Metab Syndr 2018;07:e236.

24 Kaduka LU, Kombe Y, Kenya E, et al. Prevalence of metabolic syndrome among an urban population in Kenya. Diabetes Care 2012;35:887-93.

25 Njelekela MA, Mpembeni R, Muhihi A, et al. Gender-Related differences in the prevalence of cardiovascular disease risk factors and their correlates in urban Tanzania. BMC Cardiovasc Disord 2009;9:e30

26 Aguilar M, Bhuket T, Torres S, et al. Prevalence of the metabolic syndrome in the United States, 2003-2012. JAMA 2015;313:1973-4.

27 Shin D, Kongpakpaisarn K, Bohra C. Trends in the prevalence of metabolic syndrome and its components in the United States 2007-2014. Int J Cardiol 2018;259:216-9.

28 Atun R, Davies JI, Gale EAM, et al. Diabetes in sub-Saharan Africa: from clinical care to health policy. Lancet Diabetes Endocrinol 2017;5:622-67.

29 Olamoyegun M, Oluyombo R, Asaolu S. Evaluation of dyslipidemia, lipid ratios, and atherogenic index as cardiovascular risk factors among semi-urban dwellers in Nigeria. Ann Afr Med 2016;15:194-9.

30 Després J-P. Body fat distribution and risk of cardiovascular disease: an update. Circulation 2012;126:1301-13.

31 Sodjinou R, Agueh V, Fayomi B, et al. Obesity and cardio-metabolic risk factors in urban adults of Benin: relationship with socioeconomic status, urbanisation, and lifestyle patterns. BMC Public Health 2008;8:e84.

32 Munyogwa MJ, Mtumwa $\mathrm{AH}$. The prevalence of abdominal obesity and its correlates among the adults in Dodoma region, Tanzania: a community-based cross-sectional study. Adv Med 2018;2018:1-8.

33 Ekoru K, Murphy GAV, Young EH, et al. Deriving an optimal threshold of waist circumference for detecting cardiometabolic risk in subSaharan Africa. Int J Obes 2018;42:487-94.

34 Kavishe B, Biraro S, Baisley K, et al. High prevalence of hypertension and of risk factors for non-communicable diseases (NCDS): a population based cross-sectional survey of NCDS and HIV infection in northwestern Tanzania and southern Uganda. BMC Med 2015;13:126.

35 Bauer UE, Briss PA, Goodman RA, et al. Prevention of chronic disease in the 21st century: elimination of the leading preventable causes of premature death and disability in the USA. Lancet 2014;384:45-52.

36 Bull FC, Maslin TS, Armstrong T. Global physical activity questionnaire (GPAQ): nine country reliability and validity study. $J$ Phys Act Health 2009;6:790-804.

37 Sreeramareddy CT, Pradhan PM, Sin S. Prevalence, distribution, and social determinants of tobacco use in 30 sub-Saharan African countries. BMC Med 2014;12:243.

38 Virdis A, Giannarelli C, Neves MF, et al. Cigarette smoking and hypertension. Curr Pharm Des 2010;16:2518-25.

39 Kanter R, Caballero B. Global gender disparities in obesity: a review. Adv Nutr 2012;3:491-8.

40 Wilcox G. Insulin and insulin resistance. Clin Biochem Rev 2005;26:19-39.

41 Wesonga R, Guwatudde D, Bahendeka SK, et al. Burden of cumulative risk factors associated with non-communicable diseases among adults in Uganda: evidence from a national baseline survey. Int J Equity Health 2016;15:e195.

42 Mfutso-Bengo J, Masiye F, Molyneux M, et al. Why do people refuse to take part in biomedical research studies? Evidence from a resource-poor area. Mal Med J 2008;20:57-63. 